\title{
Contribuições da educação não formal no aprendizado sobre Geodiversidade: Projeto Geodiversidade na Educação
}

\author{
Contributions of non-formal education in learning about Geodiversity: Geodiversity in Education Project \\ Carla Silvia Pimentel ${ }^{1}$, Antonio Liccardo ${ }^{1}$, Kleverson Gonçalves Maieski ${ }^{1}$, Camila Priotto Mendes ${ }^{1}$ \\ 1 - Depto. Geociências, Univ. Est. Ponta Grossa, UePG, Av. Gal. Carlos Cavalcanti, 4.748, Campus Uvaranas, 84030-900, Ponta Grossa PR. \\ E-MAll: CPIMENTEL@UePG.BR EalicCardo@Uepg.BR
}

\begin{abstract}
The project "Geodiversity in Education" has been developing actions in non-formal education field since 2011. Among them, organized an exhibition of geological material, similar to a museum, which try to develop Geoscience Education, Heritage Education and Environmental Education based on the knowledge of geodiversity. After consolidation of the project, the research sought to identify effective contributions in professional training of students-monitors of the Geography courses and students-visitors' learning. The results revealed that the project's actions contributed effectively in the performance of students in the course and/or in professional life, in addition bringing contributions to personal improvement. Evaluation aims the project meets your function in non-formal education, disseminating scientific knowledge to the community and developing supplementary products. About students who visited the exhibition, their teachers answers showed direct correlation between contents of the exhibition and those taught to his students in lessons, declaring that the project is motivating and didactically adequate.
\end{abstract}

Manuscrito:

Recebido: $27 / \mathrm{fev} / 18$

Corrigido: $8 /$ ago/18

Aceito: $10 / a g 0 / 18$

Citation:Pimentel C.S, Liccardo A., Maieski K.G., Mendes C.P.. 2018. Contribuições da educação não formal no aprendizado sobre Geodiversidade: Projeto Geodiversidade na Educação. Terræ Didatica, 14(2):225-232. URL: http://www.ige. unicamp.br/terraedidatica/.

Keywords: Geodiversity, non-formal education, geological heritage, geosciences.

\section{Introdução}

Desde 2011 está em contínua atividade o projeto de extensão "Geodiversidade na Educação", criado por docentes do Laboratório Didático de Geologia do Departamento de Geociências (DEGEO) da Universidade Estadual de Ponta Grossa (UEPG). Como principais características, a proposta apresenta uma exposição de amostras que recebe visitantes, muitas vezes agendados com monitoramento de alunos bolsistas e voluntários e ações voltadas à divulgação para a sociedade.

O projeto fundamenta-se na concepção de extensão, contudo desenvolve ações concomitantes de pesquisa e de ensino e busca, essencialmente, promover conteúdos de geociências para a Educação Básica e Superior e para a popularização da ciência.

A equipe que criou e mantém as ações do projeto é composta por docentes do DEGEO (geólogos e geógrafos com especialização em educação e cartógrafos) e por alunos-monitores bolsistas, do curso de Geografia (Bacharelado e Licenciatura).
A formação dos alunos-monitores se dá durante as ações no projeto, que envolvem estudos no Laboratório Didático de Geologia, reuniões de trabalho e soluções de problemas específicos da exposição, participação em eventos científicos da área, desenvolvimento de materiais didáticos e pesquisas. Os conceitos de educação patrimonial e ambiental embasam as produções e a abordagem expositiva, já que o acervo tem qualidade museológica e sua valorização é discutida atualmente como patrimônio geológico ex situ (Ponciano et al. 2011). Como "fragmentos do meio ambiente" trazem um conteúdo informativo sobre a geodiversidade, de fácil correlação com as questões de preservação.

As ações de ensino e divulgação de conhecimentos acontecem por processos característicos de educação não formal, o que não só possibilita, mas também favorece o vínculo permanente com a comunidade em geral (compreendendo diferentes públicos escolares e não escolares).

Além de proporcionar um novo espaço de estudos e pesquisas no campo da geologia/geografia, o 
projeto tem promovido a integração de estudantes e professores de diferentes áreas e criou uma nova interface da universidade com o ensino fundamental e médio. O uso de várias mídias e linguagens contribui para tornar os conceitos geocientíficos compreensíveis aos diferentes públicos, potencializando os valores vinculados ao patrimônio geológico/geográfico.

Uma investigação, ao longo dos anos de existência do projeto, vem sendo desenvolvida no sentido de compreender os impactos desta estratégia sobre os sujeitos envolvidos no processo.

\section{Metodologia}

Em 2014 foi realizado um levantamento (Liccardo et al. 2015) junto ao público visitante da exposição (externo e alunos de vários cursos usuários do Laboratório de Geologia) com o escopo de avaliar os seus impactos. Foram 474 pessoas consultadas (com questionário semiestruturado), dos quais 250 eram visitantes externos e 224 alunos da UEPG. Do grupo de visitantes em geral, $81 \%$ declararam terem tido pouco ou nenhum contato anterior com o conteúdo da exposição e 94,4\% afirmaram que houve aprendizado sobre a temática após a visitação.

Do grupo de usuários do laboratório, que na época eram alunos dos cursos de Agronomia, Geografia (Licenciatura e Bacharelado) e Ciências Biológicas (Licenciatura e Bacharelado), 70\% declararam não ter tido contato anterior com o tema e $89 \%$ afirmaram que a exposição contribuiu para um melhor desempenho nas disciplinas específicas e correlatas de seus cursos. Em uma variação de notas de 0 a 5, 83\% atribuíram índices 4 e 5 para a importância desta exposição como suporte para seus estudos (Liccardo et al. 2015).

A partir deste panorama, novas análises foram desenvolvidas no âmbito do projeto, organizadas em dois eixos. O primeiro considera os saberes profissionais adquiridos pelos alunos do curso de Geografia, que atuam como monitores no projeto, tendo-se em conta a ótica pessoal de cada um (Pimentel \& Liccardo 2017). Os sujeitos colaboradores da pesquisa foram 19 alunos do curso de Geografia, dos 27 alunos que integraram o projeto entre 2011 a 2017. Destes, 15 foram/são alunos do curso de Licenciatura, sendo sete mulheres e oito homens e 4 foram/são alunos do curso de bacharelado, sendo três mulheres e um homem. As idades variaram entre 18 e 33 anos. Deste grupo, seis alunos-monitores ainda compõem a equipe.
O segundo eixo considera as contribuições na aprendizagem de alunos-visitantes da Educação Básica sobre elementos da geodiversidade, sob a ótica de seus professores (Maieski 2017). Neste sentido colaboraram com a pesquisa 10 professores da Educação Básica, que, em 2017, levaram suas turmas para visita guiada na exposição "Geodiversidade na Educação". Deste grupo, $60 \%$ atuam em escolas da rede pública e $40 \%$ atuam em escolas da rede privada, sendo 08 mulheres e 02 homens. $\mathrm{O}$ grupo é formado por $30 \%$ de professores iniciantes (com menos de três anos de docência), 30\% de professores que atuam na docência entre $10 \mathrm{e}$ 20 anos e $40 \%$ deles atuam como professores há mais de 20 anos. Deste grupo 40\% dos docentes trouxeram turmas do Ensino Fundamental para a visitação, 30\% turmas do Ensino Médio, 10\% turmas do Fundamental - séries iniciais e também 10\% trouxe turma do Ensino Superior.

Esta pesquisa se fundamentou em uma abordagem qualitativa, valorizando as representações de alunos e professores sobre as aprendizagens decorrentes das ações do projeto.

Para dar tratamento aos dados e informações utilizou-se a Metodologia de Análise de Conteúdo (Bardin 2007), tendo sido observadas as seguintes fases: a) Pré-análise, etapa de organização do material coletado apoiada em ideias iniciais, neste caso delimitadas pelos elementos a serem investigados: saberes e aprendizagens; b) Determinação das unidades de análise e unidade de contexto, também guiados pelos interesse das pesquisas; c) Categorização e d) Descrição e interpretação, etapas em que foram utilizados registros dos sujeitos colaboradores das investigações (mantendo o sigilo de autoria). Para ambos os grupos investigados o instrumento de coleta de dados e informações foi um questionário semiestruturado, sendo que para os 06 docentes o instrumento foi entregue em mãos, logo após a visita e para os demais foi enviado por e-mail, acessando o cadastro dos docentes que agendaram visitas à exposição.

\section{O Projeto Geodiversidade na Educação}

A proposta do projeto Geodiversidade na Educação, que procura levar conhecimentos de geodiversidade à comunidade em geral e fomentar novos conhecimentos na comunidade universitária, teve como primeira ação a implementação de uma exposição permanente de material geocientífico (amostras, objetos, maquete, mapas, painéis, textos

\begin{tabular}{c|c|c|c|c|c}
\hline (C) Terrae Didat. & Campinas, SP & v.14 & n.3 & p. 225-232 & jul./set. 2018 \\
\hline
\end{tabular}



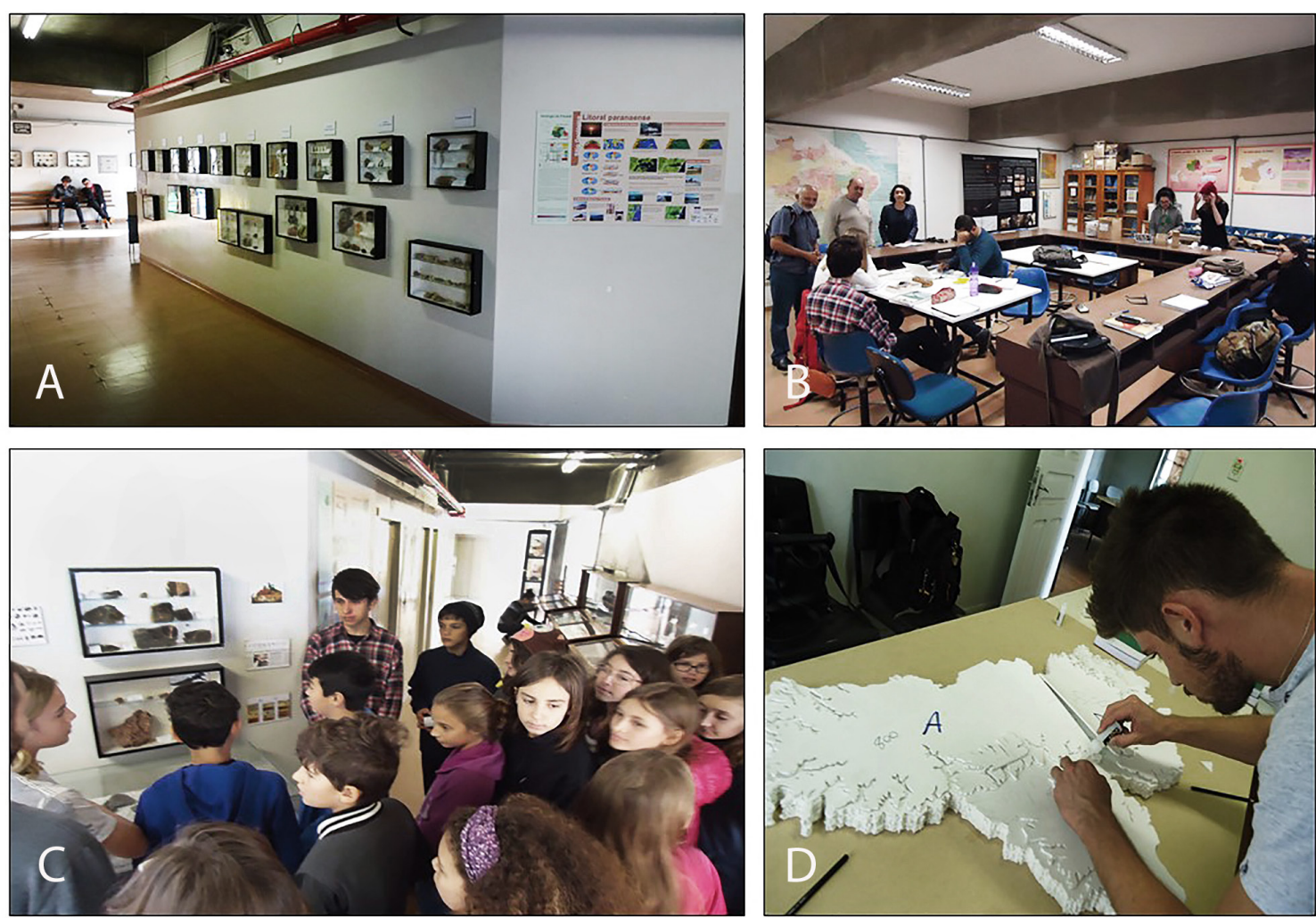

Figura 1. A exposição temática sobre geodiversidade instalada em saguão e corredores da universidade proporciona acesso livre e contínuo. A - Elementos da geodiversidade expostos em vitrines. B - Atividades do projeto em laboratório. C - Escolares em visita monitorada. D - Elaboração de materiais didáticos como maquetes

e imagens) em áreas de passagem na UEPG (Figura 1). Compõem a exposição amostras de minerais, rochas, meteoritos, fósseis e artefatos arqueológicos que buscam revelar a geodiversidade de diferentes lugares do mundo, porém com destaque local e regional (Liccardo \& Guimarães 2014).

Consolidado o acervo e a rotina de visitação, outras ações foram gradualmente implantadas, como a criação e manutenção de um website (www. geocultura.net) com repositório virtual, a criação de kits didáticos (minerais e fósseis), a produção de cartilhas e vídeos explicativos, a instalação de painéis geodidáticos sobre os principais geossítios do Paraná, a confecção de maquetes do Paraná e de Ponta Grossa, além de participação eventual em eventos e feiras externos à universidade.

Ao longo desses seis anos de existência do projeto constatou-se crescente interesse da comunidade externa da UEPG em visitar a exposição. Este fato exigiu a organização de roteiros para recepção de escolas e grupos de diferentes interesses que buscam conhecimentos sobre geodiversidade. Foram realizadas parcerias com o PIBID/Licenciatura em Geografia (Programa Institucional de Bolsas de Iniciação à Docência) que promoveu Mostras de
Geologia em escolas de Educação Básica e com o NUTEAD (Núcleo Tecnológico de Educação à Distância) - Licenciatura em Geografia (modalidade EAD), que viabilizou a criação de produtos didáticos e vídeos, além de uma gradual inserção no ensino à distância.

\section{Educação não formal e produção de conhecimentos}

A exposição contempla cerca de 1.200 amostras, organizadas em nichos com características museológicas. Minerais, rochas, fósseis, artefatos arqueológicos, mapas, maquetes e outros objetos relacionados são elementos que possibilitam o estudo do meio natural por especialistas ou facilitam sua compreensão por leigos. O caráter museológico é uma correlação que pode ser estabelecida pela forma de apresentação e organização dos materiais do projeto e pelo caminhamento resultante na visitação por grupos. Segundo Chagas (1993), na atualidade os museus apresentam as funções de aquisição, conservação e divulgação, sendo esta última uma função educativa, o que ganha evidência na investigação aqui realizada. 
A atuação dos alunos-monitores se dá por meio de ações eventuais e permanentes ofertadas no âmbito do projeto: confecção de produtos, participações em eventos científicos e de divulgação do projeto na comunidade local, organização da exposição das amostras e recepção aos visitantes com explicações teórico-práticas dos materiais expostos e das pesquisas. As atividades de ensino, ligadas à participação e aprendizado profissional desses alunos, e a forma como apresentam os materiais aos visitantes, acontecem com características de educação não formal, não obstante o espaço esteja inserido em uma instituição de ensino formal. Para organizar a recepção aos visitantes os alunos-monitores seguem um texto-roteiro que lhes permite guiaras pessoas com diferentes níveis de ensino (Fundamental, Médio e Superior).

A caracterização da exposição como espaço não formal de educação, está em sintonia com o que é apregoado por vários autores, como Severo (2015, p.568), que conceitua a educação "como um fenômeno complexo, disperso, heterogêneo, sobre o qual se denomina uma multiplicidade de práticas e resultados formativos" e com López (1996, p.76) que, ao utilizar o critério extraescolar, define educação não formal como "el proceso de aquisición y el conjunto de competencias, destrezas y actitudes educativas adquiridas con estímulos directamente educativos en actividades no conformadas por el sistema escolar".

Dentre as várias dimensões deste tipo de educação destaca-se "a aprendizagem de conteúdos que possibilitem aos indivíduos fazerem uma leitura do mundo do ponto de vista da compreensão do que se passa ao seu redor" (Gohn 2006, p. 28), a partir da interação com o "outro" que media o processo de aprendizagem. Esta é a essência que fundamenta também as ações de conscientização patrimonial. A educação não formal caracteriza-se, também, por espaços e/ou atividades organizados coletivamente e diferenciados daqueles organizados pelas escolas pelo currículo formal, mas que mantêm a característica de espaços onde há processos educativos intencionais (Gohn 2006, Bianconi \& Caruso 2005). Estas características estão presentes na filosofia e no cotidiano do projeto.

As práticas promovidas pelo Projeto Geodiversidade na Educação, contemplam conhecimentos presentes nos currículos oficiais da Educação Básica e Superior e ocorrem, em sua maioria, em espaço físico escolar (UEPG), mas com contornos de educação não formal porque os conteúdos transmitidos na exposição não seguem uma padronização imposta. Essa característica "facilita a possibilidade de métodos e estruturas organizacionais muito mais abertas" (Trilla \& Arantes 2008, p. 42), pois a interação dos visitantes com o conhecimento apresentado (conceitos/contextos/fenômenos) gera diferentes processos de ensino, que são conduzidos pelos alunos-monitores, sem que a ação siga as normalizações e convenções de práticas escolares formais. Essas mesmas ações acabam por promover o desenvolvimento profissional dos alunos-monitores, por conta da dinamização que o conteúdo requer para sua apresentação. Entretanto, é necessário ressaltar que o conhecimento obtido durante a visitação não substitui o conhecimento derivado da educação formal, mas "aparece como uma espécie de complementaridade, uma espécie de partilha de funções, de objetivos, de conteúdos entre os diversos agentes educativos" (Trilla \& Arantes 2008, p. 46). As ações promovidas pelo projeto têm acrescentado aos visitantes uma percepção da geodiversidade que se diferencia dos formatos apresentados pelas escolas e esta pesquisa aponta um efetivo papel complementar na educação formal.

\section{Aprendizagens profissionais: 0 caso dos alunos-monitores}

Para uma avaliação das aprendizagens formativas propiciadas pelo projeto aos alunos-monitores foram coletados dados e informações que contemplam as categorias: conhecimentos e habilidades científicas; conhecimentos e habilidades para a docência; desenvolvimento pessoal e dificuldades enfrentadas no projeto, todas pré-determinadas. Estas categorias apresentaram subcategorias definidas, havendo possibilidade de os alunos-monitores inserirem outras que achassem necessárias. As questões foram organizadas para que os sujeitos pudessem indicar níveis/ graus de aprendizado, que variaram entre 1 e 5 (do menor para o maior grau). Além dessas questões o questionário contemplou uma questão aberta: "Qual a sua opinião sobre as possibilidades formativas do projeto Geodiversidade na Educação"?

Ao tabular e analisar os dados gerados pelas questões fechadas surgiram indicativos elevados de aprendizado na grande maioria dos quesitos apresentados. Também não houve distinção entre os dados apresentados pelos alunos da licenciatura daqueles apresentados pelos alunos do bacharelado. Desta forma, foram retiradas da questão aberta as considerações do grupo que atendessem as categorias definidas pela pesquisa.

\begin{tabular}{c|c|c|c|c|c|}
\hline (C) Terrae Didat. & Campinas, SP & v.14 & n.3 & p. 225-232 & jul./set. 2018 \\
\hline
\end{tabular}


Os resultados permitiram uma avaliação geral do desenvolvimento de saberes ligados à profissão de professor e de bacharel que os alunos acreditam ter adquirido ou fomentado a partir de sua participação no projeto. No âmbito dos conhecimentos e habilidades científicas (categoria) destacam-se nos registros dos alunos a oportunidade de aprendizado do conteúdo geológico, produção de materiais e realização de pesquisas. Algumas falas revelam essas percepções:

Durante minha participação no projeto tive experiências significativas para poder exercer minha profissão como bacharel em Geografia [...] atuando em área a qual o conhecimento sobre geologia era necessário, o que adquiri com o projeto. (Aluna B4)

O conjunto de atividades desenvolvidas a partir do referido projeto é significativamente diversificado nas suas proposições formativas, possibilitando o desenvolvimento de aptidões várias como a confecção, manejo e mediação de materiais/ saberes didáticos, assim como o exercício crítico e reflexivo deveras necessário à prática científica (Aluno L15)

[...] proporciona aos discentes que estão no curso a oportunidade de pesquisa e produção científica. (Aluna L2)

$\mathrm{Na}$ categoria conhecimentos e habilidades destacaram-se as habilidades de transmissão de conhecimentos para grupos, com ênfase para grupos escolares. É interessante ressaltar que mesmo os alunos do bacharelado constataram este aprendizado, conforme as seguintes falas:

Especificamente para o futuro professor de geografia, o projeto geodiversidade na educação possibilita o contato com alunos do ensino básico (Ens. Fund. e Médio), normalmente com os quais trabalhará após a formação. Contribui para a desenvoltura dos acadêmicos em casos de apresentação dos conteúdos relacionados à geologia e demais campos do conhecimento, estimula a curiosidade para as geociências e permite vislumbrar diferentes formas de se ensinar e aprender geologia. (Aluno L10)

Acredito que este projeto tem alta potencialidade de transmissão de conhecimento para o ensino regular, como tem a capacidade de ampliar o conhecimento discente, tanto de licenciandos quanto de bacharelandos, pela interação e acesso a novas formas de produção do conhecimento. (Aluno B2)
Sobre os conhecimentos de base para a docência (Shulman 2005) pode-se considerar que houve aprendizado de conteúdo geológico (que compõe a área de Geografia no currículo oficial da Educação Básica), certo conhecimento dos alunos e suas características e também conhecimento didático, referindo-se aqui sobre a relação idade dos alunos da escola básica-conteúdos-linguagem-aprendizado, que foram os saberes evidenciados por eles.

$\mathrm{Na}$ categoria desenvolvimento pessoal alguns alunos-monitores apontam valores, saberes e atitudes estritamente ligados à profissão, indo além das categorias apresentadas no questionário, tais como: "desenvolvimento educacional" (Aluno L7); "consolidação de habilidades para a docência fora do ambiente escolar" (Aluno L12) e "interação com profissionais de diferentes áreas, estreitamento com o ambiente universitário e escolar e gestão de múltiplas habilidades" (Aluna L13). Podemos definir essa generalidade de saberes como "competências complexas" (Contreras 2002), tão valiosas para o exercício profissional quanto os saberes clássicos de um docente, bem como o estabelecimento/ reconhecimento das relações interpessoais, fundamentais para o amadurecimento profissional. Estes elementos são significativos para dar sustentação emocional e possibilitar a transição de neófitos à experientes em uma função.

Por fim, três dificuldades enfrentadas no âmbito do projeto se destacaram: produção de materiais didáticos para escolares, linguagem científica para leigos, além de domínio de conteúdos e teorias, dificuldades que os gestores do projeto buscam sanar na medida em que as ações são propostas. Uma aluna aponta a falta de disponibilidade de recursos (Aluna L13), questão que esbarra na ausência de financiamento para as ações do projeto, à exceção das bolsas para alguns dos integrantes.

\section{Contribuições para alunos da escola básica}

Outro eixo da pesquisa buscou obter informações sobre as contribuições geradas aos alunos das escolas visitantes. Aqueles que procuram a exposição possuem diferentes objetivos, perspectivas e conhecimentos, o que dificulta análises quantitativas sobre as contribuições do projeto. Não existem, até o momento, dados substanciais que possam indicar o quanto essa exposição está contribuindo efetivamente para a divulgação e/ou construção de conhecimentos sobre a geodiversidade.

Em virtude das características inerentes à

\begin{tabular}{c|c|c|c|c|c|}
\hline (C) Terrae Didat. & Campinas, SP & v.14 & n.3 & p. 225-232 & jul./set. 2018 \\
\hline \multicolumn{2}{|c|}{229}
\end{tabular}


educação não formal, os dados observados empiricamente durante as visitas não permitem fácil quantificação e precisão. Desta forma, optou-se também pela aplicação de questionários, dirigidos principalmente aos educadores, o que resultou em importantes informações sobre o alcance do projeto.

O objetivo foi analisar possíveis aprendizagens que escolares obtêm na experiência de visitação à exposição e reconhecer as possibilidades formativas do projeto sob a ótica do professor da Educação Básica. Há preocupação constante em refinar o processo de transmissão de informações à sociedade, à semelhança do que acontece em espaços museológicos modernos, pois como destaca Andrés (2016), os museus dos tempos atuais vêm dando ênfase aos valores sociais.

A exposição "Geodiversidade na Educação" busca atuar como um instrumento educacional, oferecendo algo à comunidade em torno da UEPG (Universidade Estadual de Ponta Grossa) e aos estabelecimentos de vários segmentos educacionais.

Como afirmam Bianconi \& Caruso (2005, p.20),

[...] o ensino não-formal tem ainda um enorme potencial a ser explorado, principalmente no que diz respeito à sua capacidade de motivar o aluno para o aprendizado - valorizando suas experiências anteriores -, de desenvolver sua criatividade e, sobretudo, de despertar o interesse do jovem pela ciência.

As questões centrais que pautaram esta etapa da investigação com os docentes tratam dos motivos e das expectativas dos docentes da Educação Básica que agendam visita guiada com seus alunos.

Ao serem questionados sobre os motivos da escolha de levar os alunos na exposição, 70\% do grupo trouxe em primeiro plano a relação direta com os conteúdos, com ênfase para a visualização e aprofundamento dos aspectos teóricos trabalhados em sala de aula. Outro destaque foi o fato da exposição manter acervo sobre a geodiversidade do estado do Paraná.

O grupo apresenta como motivos secundários para a visitação: "ser um espaço público e de baixo custo para uma visita [...]" (Professor 08); “contar com um acervo primoroso e pessoal bem qualificado para receber os grupos" (Professora 09); permitir "que os alunos já estabeleçam intimidade com o lugar" (Professora 10) - referência que esta última docente faz para o fato dos alunos terem o primeiro contato com a universidade. Neste quesito não houve distinção entre os docentes dos diferentes níveis, exceto pela docente do Ensino Superior que incluiu a visita em um projeto de campo realizado com seus alunos no Estado do Paraná, sendo eles de uma universidade do estado de São Paulo.

As respostas permitem constatar que o projeto configurado no modelo não formal de educação consegue estabelecer relações diretas com os conteúdos escolares, pois $100 \%$ dos professores apontaram que os conteúdos trabalhados na exposição estão presentes no currículo escolar e são vistos em sala de aula. Foram especificados: minerais, tipos de rochas, fósseis, geomorfologia, evolução da Terra, coluna estratigráfica, impactos ambientais, recursos minerais, formação geológica e meteoros.

No currículo oficial para as escolas públicas do Paraná, constatou-se que em todos os níveis existe uma aproximação em relação ao conteúdo, principalmente no que concerne à dimensão socioambiental proposta pelas Diretrizes Curriculares Estaduais:

Este conteúdo estruturante perpassa outros campos do conhecimento, o que remete à necessidade de situá-lo de modo a especificar qual seja o olhar geográfico de que se trata. [...] Os impasses ambientais que inquietam o mundo de maneira mais explícita, desde os anos de 1960, custaram a ganhar espaço no pensamento geográfico. Essa dificuldade se deu, de acordo com Mendonça (2001), em função de alguns fatores como: • a secundarização dos aspectos físicos do espaço geográfico, a partir da década de 1970, com a emergência da ideia da Geografia como ciência social; • a consequente recusa da importância da dinâmica da natureza "na constituição do espaço, do território e da sociedade"; • a fé na ciência e na tecnologia como potencialmente capazes de resolver os problemas ambientais gerados pelo modo de produção capitalista. (Paraná 2008, p. 71-72)

O trabalho realizado pelos monitores dentro do laboratório e nos nichos temáticos foi avaliado como motivador e didático-pedagógico. Outra característica destacada pelos professores do Ensino Fundamental e médio é estar adequado ao grupo. Neste sentido houve por parte da coordenação a organização de materiais teóricos para subsidiar as explicações para diferentes grupos escolares, o que parece ter alcançado validade. Em relação ao tempo de visitação $90 \%$ do grupo considerou adequado e a docente, que levou a turma do Ensino Superior, considerou o tempo curto, porém determinado por sua própria agenda. Houve por parte de um docen- 
te do grupo a sugestão de produção de material impresso, para ser entregue aos visitantes.

Concluiu-se, após a análise dos questionários, que: os professores visitantes reconhecem o projeto Geodiversidade na Educação como adequado para os seus alunos, mesmo sendo um espaço típico da educação não-formal; o conteúdo que tem sido apresentado em cada nicho da exposição e o trabalho prático no laboratório tem mantido coerência com o que é trabalhado na educação formal; o projeto é considerado motivador e didático/pedagógico, tanto no trabalho realizado no interior do laboratório quanto nos nichos.

\section{Considerações Finais}

O Projeto Geodiversidade na Educação está em atividade contínua há cerca de sete anos e a exposição de amostras (uma das ações do projeto) recebeu cerca de 10 mil visitantes de Ponta Grossa e região. São visitas com variados objetivos e perspectivas e que envolveram alunos de todos os níveis da educação básica e ensino superior, o que requer diferentes abordagens sobre os diferentes temas para atender às expectativas de aprendizagem desses níveis.

O projeto tem a finalidade de divulgar os conteúdos geocientíficos consolidando noções de geoconservação e patrimônio ambiental. A geodiversidade ainda é um tema incógnito ao público geral e aos acadêmicos dos primeiros anos do curso de Geografia em grau de licenciatura ou bacharelado. Porém, as graduações de Geografia e Geologia no Brasil têm se empenhado para otimizar essa temática em virtude da demanda de conhecimentos acerca do meio ambiente para o planejamento territorial. Busca-se constantemente familiarizar as geociências com o público em geral.

O projeto tirou dos laboratórios os conteúdos acumulados em gavetas e os expôs para que mais pessoas possam acessá-los, possibilitando a interdisciplinaridade, que é tão cara e por isso priorizada pela produção na ciência da contemporaneidade. Democratizar o acesso ao conhecimento geológico é o primeiro passo na busca de sensibilizar a população para proteger o patrimônio geológico e, nesse ponto, o projeto tem solidificado suas ações. O que se espera é que cada escola que visite a exposição leve consigo a sensibilidade para observar e reconhecer aspectos particulares da paisagem e que cada universidade leve o exemplo para externalizar a sua produção científica e promover o acesso à ciência para o público em geral.

Trabalhos de conclusão de curso e iniciações científicas também se desenvolveram dentro deste projeto, assim como artigos e publicações em eventos e periódicos. Enquadrado como extensão universitária, o projeto gerou importantes desdobramentos também na pesquisa e ensino correlatos.

A análise dos resultados do questionário indicou alguns ganhos em termos de preparo profissional dos alunos-monitores. Com base nas categorias utilizadas foi possível reconhecer qualitativamente em quais aspectos o projeto contribui na sua formação. Não obstante o tempo de participação no projeto, que foi bastante variável, há unanimidade em que algumas habilidades desenvolvidas em seu âmbito contribuíram para um melhor desempenho dos alunos no curso e/ou na vida profissional, além de aportes para o desenvolvimento pessoal.

A prática de monitoria de visitação também se mostrou mais próxima de licenciandos, como exercício futuro da profissão. No entanto, a mesma prática de monitoria para bacharelandos contribuiu para o desenvolvimento pessoal, conforme os relatos dos participantes. Eles avaliam que o projeto cumpre bem sua função extensionista, divulgando conhecimento científico à comunidade em geral e desenvolvendo produtos que possam atender diferentes demandas dentro da temática trabalhada.

Outro aspecto que merece relevo é o destaque dado ao desenvolvimento pessoal possibilitado pelo projeto. Como sugestão eles apontam que seja inserido no site do projeto um campo que registre o histórico das ações e dos participantes.

Também os resultados trazidos por docentes, que levam suas turmas para visitas guiadas no projeto, contribuíram para o reconhecimento da validade das ações, bem como apontaram necessidades que ainda não foram contempladas. Os docentes indicam contribuições efetivas do projeto em sua vertente educativa, confirmando uma correlação direta entre os conteúdos apresentados no âmbito da exposição e aqueles ensinados aos seus alunos e ainda, que a forma como são transmitidos é motivadora e didaticamente adequada. Esses são resultados preliminares de uma investigação que deverá se aprofundar, mas que trazem parâmetros para balizar novas ações do projeto.

As características do espaço e o formato em que é executado permitem compreendê-lo no âmbito da educação não formal (Gohn 2006, Trilla \& Arantes 2008), mesmo sendo gerido e executado em espaço formal de ensino.

\begin{tabular}{c|c|c|c|c|c|}
\hline (C) Terrae Didat. & Campinas, SP & v.14 & n.3 & p. 225-232 & jul./set. 2018 \\
\hline
\end{tabular}




\section{Referências}

Andrés R. M. 2016. La Educación Patrimonial em Los Museos Industriales Espanõles: Estado de La Cuestión y Propuestas para Su Desarrolo y Evaluación, Revista Didácticas Específicas, 15:108-125.

Bardin L. 2007. Análise de conteúdo. Lisboa: Edições 70.

Bianconi M. L., Caruso F. 2005. Educação não formal. Ciência e cultura: temas e tendências, 57(4).

Chagas I. 1993. Aprendizagem não formal/formal das ciências. Relação entre os museus de ciências e as escolas. Lisboa, Revista de Educação. 3(1):51-59.

Contreras J. 2002. A autonomia de professores. São Paulo: Cortez.

Gohn M.G. 2006. Educação não-formal, participação da sociedade civil e estruturas colegiadas nas escolas. Ensaio: aval. pol. públ. Educ., 14(50):27- 38.

Liccardo A., Guimarães G.B. orgs. 2014. Geodiversidade na Educação. Ponta Grossa: Estúdio Texto.

Liccardo A., Pimentel C. S., Guimarães G.B., Pidhorodeski G., Almeida S.A., Alessi S.M., Oliveira M. Carneiro R.T. 2015. Exposição de conteúdos geocientíficos como possibilidade de Educação em Patrimônio Geológico. Terrae Didatica, 11(3): 182188.

López J.M.T. 1996. Análisis conceptual de los procesos educativos. «formales», «no formales» e «informales». Teor. educ., Ediciones Universidad de Salamanca, 8:55-79.

Maieski K.G. 2017. Educação não-formal e o projeto Ge- odiversidade na Educação - UEPG. Ponta Grossa: UEPG. (Trab. Concl. Curso ).

Mendonça F. 2001. Geografia sócio-ambiental. Terra Livre, 16:113-132.

Paraná. Secretaria de Estado da Educação. 2008. Diretrizes Curriculares da Educação Básica do Paraná - Geografia. Curitiba: SEED.

Pimentel C.S., Liccardo A. 2017. Formação profissional em ações de extensão - contribuições do projeto Geodiversidade na Educação. Anais do IV Simpósio Brasileiro de Patrimônio Geológico e II Encontro Luso-Brasileiro de Patrimônio Geomorfológico e Geoconservação. GUPE: 142-146p.

Ponciano L.C.M.O., Castro A.R.S.F., Machado D.M.C., Fonseca, V.M.M., Kunzler J. 2011. Patrimônio Geológico-Paleontológico e: Definições, vantagens, desvantagens e estratégias de conservação. In: Carvalho I.S. et al. eds. Paleontologia: Cenários de Vida. Ed. Interciência, 4:853-869.

Severo J.L.R.L. 2015. Educação não escolar como campo de práticas pedagógicas. Rev. Bras. Est. Pedag. (online), 96(244):561-576.

Shulman L.S. 2005. Conocimiento y enseñanza: fundamentos de la nueva reforma. Profesorado. Granada-España, Revista de Currículum y Formación del Profesorado, 9(2)1-30. URL: https://www.ugr. es/ recfpro/rev92ART1.pdf. Acesso 02.06.2017.

Trilla J., Arantes V.A. orgs. 2008. Educação formal e não-formal: pontos e contrapontos. São Paulo: Summus. $167 \mathrm{p}$. 